\title{
Temporal order: The effect of single versus repeated presentations, practice, and verbal feedback'
}

\author{
ROY W. GENGEL ${ }^{2}$ AND IRA J. HIRSH \\ CENTRAL INSTITUTE FOR THE DEAF
}

\begin{abstract}
Whereas Hirsh and Sherrick (1961) found that experienced Os could judge correctly the temporal order of a sound and a light presented repeatedly when the interval separating them was $20 \mathrm{msec}$, Hirsh and Fraisse (1964) found that naive Os required about $60 \mathrm{msec}$ for the same accuracy of performance with single presentations of the same pair. This experiment examined the effects of single us repeated presentations, practice, and verbal feedback on performance in the judgment of temporal order. The results indicate that performance under repeated presentation is significantly better than under single presentation, that learning effects are most pronounced during the first 4 of 16 sessions, and that the effects of feedback appear to depend on the precise wording given the $S$ on how he is to perform.
\end{abstract}

Hirsh and Sherrick (1961) reported that an interval of about $20 \mathrm{msec}$ between the onsets of a sound and of a light is necessary for Ss to report temporal order with $75 \%$ accuracy. On the other hand, Hirsh and Fraisse (1964), also pairing sound and light, reported a $60-\mathrm{msec}$ interval for $75 \%$ accuracy.

Whereas Hirsh and Sherrick presented the stimuli repeatedly until $S$ reported his judgment, Hirsh and Fraisse gave only a single presentation of the pair per response. Furthermore, while Hirsh and Sherrick used experienced Ss, Hirsh and Fraisse used naive Ss. Although it is known that repeated presentations of stimuli can enhance performance in psychophysical experiments (Schreitmueller, 1952; Swets, Shipley, McCay, \& Green, 1959), it is not clear (1) how much enhancement repeated presentations will provide when training effects are equalized, and (2) to what degree performance can be improved with practice under conditions of single and repeated presentations of stimuli.

The main purposes of this experiment are (1) to compare single with repeated presentation for performance in judging temporal order, and (2) to examine the effect of practice on performance. In addition, a third purpose is to study the effect of verbal feedback on performance, especially under the more difficult condition of single presentation of stimuli.

\section{Apparatus \\ Stimuli and test environment were} essentially those described by Hirsh and Fraisse. The interval between onset of click and light was controlled by two Tektronix Type 161 pulse generators, triggered by a Tektronix Type 162 waveform generator. The waveform generator was externally triggered.

A tuned circuit, consisting of a $12-\mathrm{H}$ inductor in parallel with a 0.01 -microfarad capacitor and a variable resistor, was excited by a $0.1-\mathrm{msec}$ positive pulse from one pulse generator to produce a damped sinusoid of $400 \mathrm{~Hz}$ with a decay time of 40 msec. The tonal transient was amplified, attenuated, and presented through a loudspeaker to Ss at 50-dB sensation level (SL).

A $0.2-\mathrm{msec}$ positive pulse from the second pulse generator served to activate a Sylvania R-1131C glow-modulator tube that illuminated a $0.7-\mathrm{cm}$ diam circle on a ground Plexiglas screen. The intensity of the light was predetermined from average intermodality brightness-loudness matches made by several Os to the $50-\mathrm{dB} \mathrm{SL}$ damped sinusoid previously described.

The Ss were tested individually while sitting in a dimly lit room facing the loudspeaker and the light source, both of which were at eye level. The loudspeaker was placed directly behind the light source and was $50 \mathrm{~cm}$ from S's ears.

In conditions where $S$ s received single presentations of the stimulus pair, a 1-in.-diam, green warning light, situated next to the light source, on S's left, momentarily flashed $1 \mathrm{sec}$ prior to the onset of the stimuli.

\section{Experimental Design}

Four conditions were used. In Condition 1, single presentations of each of the stimuli were given and Ss were told after each judgment that they were "correct" or "wrong" (feedback). In Condition 2, single presentations were given but without feedback. In Condition 3 , repeated presentations of stimuli were given, and feedback was given after the response. In Condition 4, repeated presentations were given but without feedback.

In each experimental session, Ss were given 20 trials each of click leading light by $60 \mathrm{msec}$, click leading light by $20 \mathrm{msec}$, light leading click by $60 \mathrm{msec}$, and light leading click by $20 \mathrm{msec}$. In addition, Ss in the single-presentation conditions received 20 presentations of click leading light by $100 \mathrm{msec}$ and of light leading click by $100 \mathrm{msec}$. Within a session, the order of presentation of stimulus pairs was random. Ss in each condition were tested for 16 sessions.

\section{Subjects and Procedure}

Each of 16 students with normal hearing and vision and no prior experience in the experimental task was quasirandomly assigned to one of four groups (two men and two women in each).

All 16 Ss were told that their task was to judge whether the click or the light started first. In addition, $S s$ in the feedback conditions were told that $\mathrm{E}$ would report if their judgment was correct or wrong. E's report was based on the physical temporal order.

In the repeated-presentation conditions, stimuli were presented once per second until $S$ reported his judgment. (The actual number of presentations varied from as few as 2-3 for some Ss to as many as $20-30$ for others. No consistent relation between number of presentations and accuracy of performance was evident.)

\section{RESULTS}

The previous results of Hirsh and Fraisse were compared with the median per cent of "click first" responses on the 1 st test day from the Ss with single presentations (Condition 2). A line of best fit (visual) was drawn through the median points of the group data, and the interpolated intervals for $75 \%$ and $25 \%$ "click first" responses were averaged to give the estimate of threshold of temporal order. The obtained value of $56 \mathrm{msec}$ agrees well with the value of $60 \mathrm{msec}$ reported by Hirsh and Fraisse.

To check the previous results of Hirsh and Sherrick, a similar analysis was done on the data obtained on the 16 th day from the Ss with repeated presentations (Condition 4). The obtained value of $14 \mathrm{msec}$ is not too far from the value of 20 msec reported by Hirsh and Sherrick. 


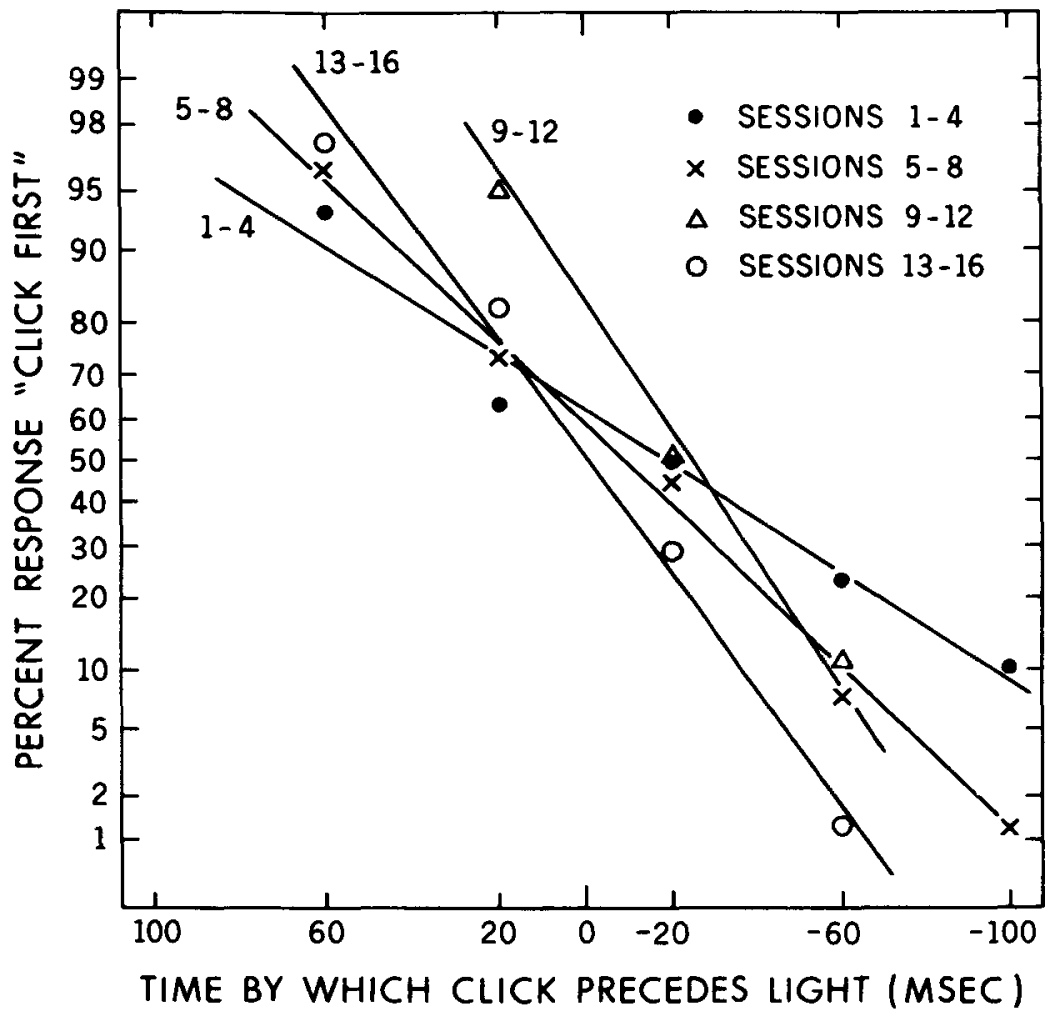

Effect of Single vs Repeated Presentation

The data within each series of 4 successive test days were averaged for each $\mathrm{S}$. These data were then plotted to obtain individual thresholds $(75 \%$ correct $)$ of temporal order. A line of best fit was drawn through each set of data, and the time intervals for $75 \%$ and $25 \%$ "click first" were averaged to estimate threshold of temporal order. An example of these plots for one $S$ arbitrarily selected from the

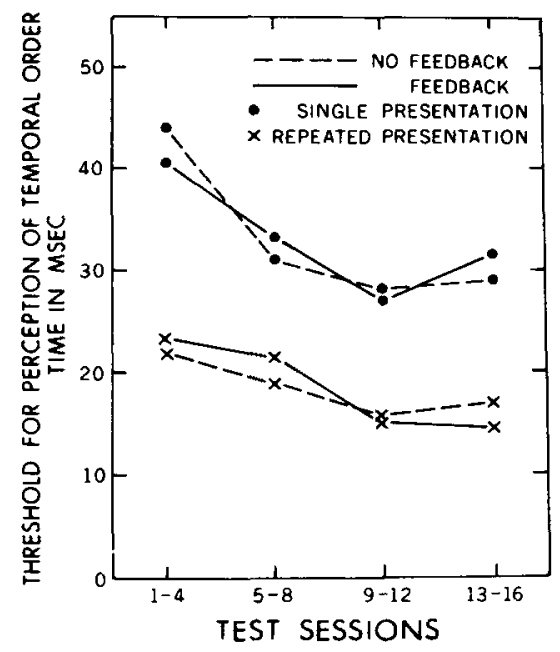

Fig. 2. Threshold for perception of temporal order as a function of test session.
Fig. 1. Example of data plots used to estimate thresholds of temporal order for one $S$.

the data were collapsed into two groups: single- and repeated-presentation conditions. (No differences in performance were found between feedback and no-feedback conditions).

Significant differences in performance were found $(p<.05)$ between Sessions 14 and Sessions 5-8 but not between subsequent sessions. Therefore, practice is only initially a significant factor determining the limen for temporal order.

\section{Effects of Feedback on Performance}

Figure 2 suggests, in addition, that feedback is not a significant variable affecting performance in judging temporal order under either single- or repeated-presentation modes of stimulus delivery. This was not especially surprising for the group that received repeated presentations of stimuli and therefore could perceive as many samples as they wished before responding. However, from conversations with $\mathrm{Ss}$ receiving single presentations with feedback (Condition 1), it was evident that some of them suspected beforehand that on some trials they would be told that their judgements were "wrong." Nevertheless, they felt that their perception of the stimulus was subjectively correct. Apparently, for these Ss, the point of subjective simultaneity of presentation of stimuli did not coincide with physical simultaneity of presentation.

To determine whether feedback could be used to teach Ss to perceive correctly the conditions of physical simultaneity, Condition 1 (single presentation with feedback) was replicated with four different Ss. These Ss were told to be "correct," that is, to attempt to label the stimuli according to the physical order of presentation. This instruction is very different from that given the group described ar uve, who were told they could ignore the, eedback if they desired.

The $r$ sults of this experiment are shown in Fig. 3, where the median scores in each set if sessions are plotted and connected by lines. The figure shows that the point of subjective simultaneity is displaced approximately $25 \mathrm{msec}$ from the point of objective simultaneity for Sessions 14 . In contrast, the points of subjective and objective simultaneity are approximately equal for Sessions 13-16.

These data show that feedback, in the form of knowledge of results, can modify performance in the judgment of temporal order. What is not clear, however, is the exact nature of this influence. For 


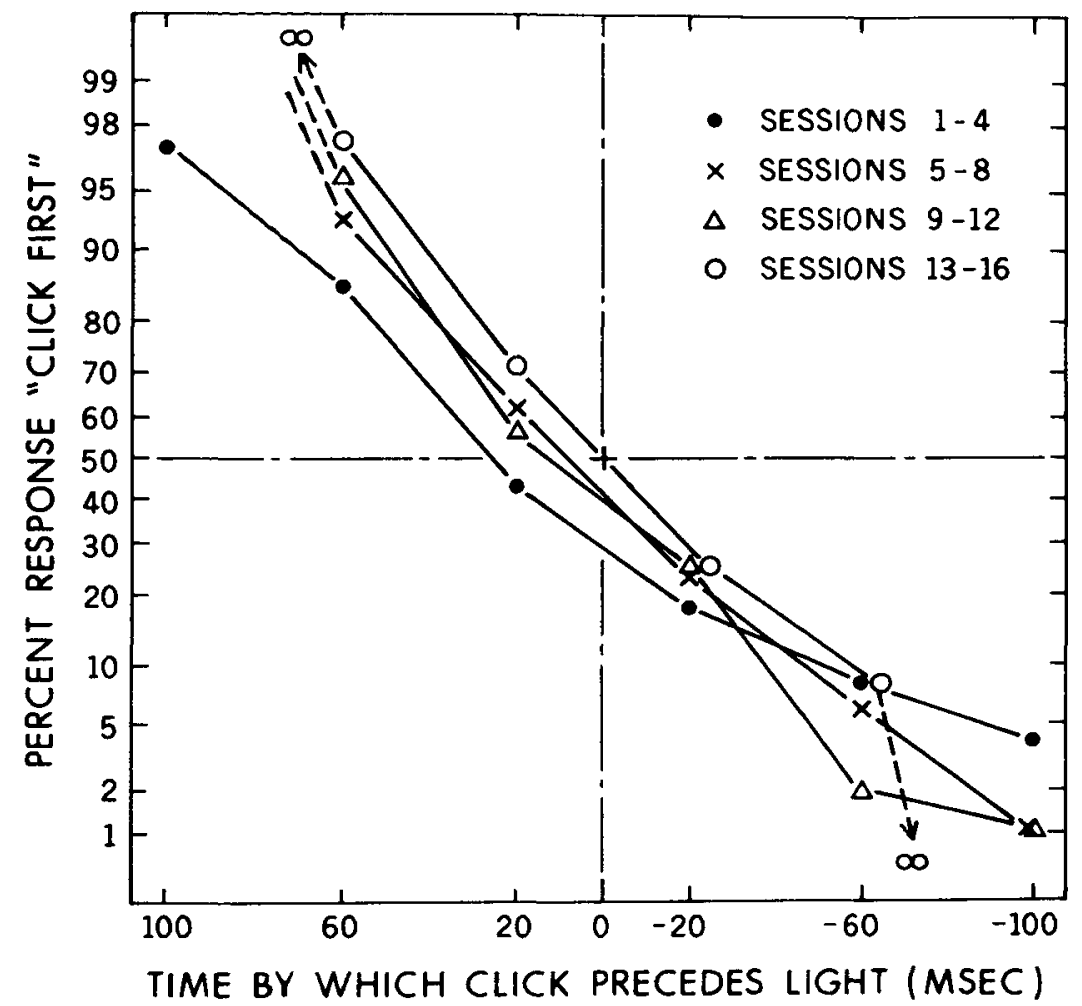

Table 1

Individual Points of Subjective Simultaneity. Each Value is the Average PSS for Sessions 13-16 of an Individual Subject.

Condition Point of Subjective Simultaneity

\begin{tabular}{rrrrr}
\hline I & $+50^{*}$ & +12 & 0 & -31 \\
IA & +5 & +3 & -4 & -9 \\
III & +6 & +6 & -6 & -6 \\
\hline
\end{tabular}

$I=$ single presentation, feedback ignored if desired

$I A$ = single presentation, feedback with instruction: "be correct"

$I I I=$ repeated presentations, feedback ignored if desired

* Values indicate time in msec by which click precedes light

example, Table 1 shows that the point of subjective simultaneity can be brought into line with the point of objective simultaneity when single presentations are followed by feedback and the $S$ is instructed to be "correct" (Condition 1A). Under Condition 1, where the $S$ could ignore the feedback, such homogenizing of performance did not result. But under Condition 3 , where repeated presentations were used and the $S$ was free to ignore feedback, results more like those of Condition 1A were obtained. Thus, there appears to be some dependence of the influence of feedback not only on instructions to $S$ concerning the use of feedback, but also on method of stimulus presentation, whether single or multiple. $17 \mathrm{msec}$ ). pp. 109-110).
Fig. 3. The effect of feedback and training on the point of subjective simultaneity in judging temporal order. The cross in the center of the graph indicates the point of objective simultaneity.

made after single presentations of stimuli.) They argue that the difference between their results and Hirsh's (1959) is due to the relatively greater experience Ss have had discriminating the onsets of formants. Similarly, it could be argued that Ss have had relatively more experience discriminating the order of two sounds than discriminating combinations of sound and light.

In conclusion, we suggest that number of presentations of stimuli is a significant factor affecting performance in judging the temporal order of light and sound. It remains a possibility that training beyond the extent given in this experiment can minimize its significance. Finally, it appears that $S$ s can be taught by verbal feedback to judge temporal order in conformity to standards set by the $\mathrm{E}$.

\section{REFERENCES}

Whereas single vs repeated presentation was found to have a significant effect in judging the temporal order of light and sound, even after training, a recent study by Homick, Elfner, and Bothe (1969) indicates that, after extensive training, Ss can judge accurately the temporal order of two sounds as well with single presentations of stimuli (threshold = $14 \mathrm{msec}$ ) as Hirsh (1959) reported for repeated presentation (threshold =

One explanation of the discrepancy of results between the present experiment and the results of Homick et al is that although bimodal (visual-auditory) and unimodal (auditory-auditory) perceptions of temporal order can be made equally well under optimum sampling conditions, under more difficult conditions, unimodal performance is superior (Fraisse, 1963,

A second explanation is that $S s$ in the single-presentation condition of this experiment were actually on a learning plateau and, with further practice, might have shown performance comparable to that found for the condition of repeated presentations. Support for this contention is found in data published by Liberman et al (1961), who found that differences of only $12 \mathrm{msec}$ between the onset of first and second speech formants could be accurately discriminated. (Judgments were
REFERENCES
FRAISSE, P. The psychology of time. New York: Harper \& Row, 1963.

HIRSH, I. J. Auditory perception of temporal order. Journal of the Acoustical Society of America, 1959, 31, 757-767.

HIRSH, I. J., \& SHERRICK, C. E. Perceived order in different sense modalities. Journal of Experimental Psychology, 1961, 62, 423-432.

HIRSH, I. J., \& FRAISSE, P. Simultaneite et succession de stimuli, heterogenes. L'Annee Psychologique, 1964, 64-19.

HOMICK, J. L., ELFNER, L. F., \& BOTHE, G. G. Auditory temporal masking and the perception of order. Joumal of the Acoustical Society of America, 1969, 45, 712-718.

LIBERMAN, A. M., HARRIS, K. S., KINNEY, J., \& LANE, H. L. The discrimination of relative onset time of the components of certain speech and non-speech patterns. Journal of Experimental Psychology, 1961, 61, 379-388.

SCHREITMUELLER, R. F. Effect of repeated presentations on the detection of signals in noise. Unpublished MS thesis, Massachusetts Institute of Technology, 1952.

SIEGEL, S. Nonparametric statistics for the behavioral sciences. New York: MoGraw-Hill, 1956.

SWETS, J. A., SHIPLEY, E. F., McCAY, M. J., \& GREEN, D. A. Multiple observations of signals in noise. Journal of the Acoustical Society of America, 1959, 31, 514-521.

\section{NOTES}

1. This research was supported by Program Project Grant 03856 from the National Institute of Neurological Diseases and Stroke to Central Institute for the Deaf.

2. Address: Central Institute for the Deaf, St. Louis, Missouri 63110.

(Accepted for publication June 4, 1969.) 